\title{
The water retention properties of a natural unsaturated loess from Northern France
}

\author{
J. A. Muñoz-Castelblanco, J. M. Pereira, P. Delage and Y. J. Cui
}

Géotechnique 2012, 62 (2), 95-106.

Ecole des Ponts ParisTech, Laboratoire Navier - CERMES, Université Paris-Est

6-8 av. B. Pascal

F-77455 Marne la Vallee cedex 2

\begin{abstract}
The water retention properties of a natural loess from Northern France were investigated on intact block samples that were excavated along a high speed train line (TGV) that experienced stability problems during heavy rain episodes. Suction measurements were made by using the filter paper method and a home made high capacity tensiometer (HCT) so as to determine the water retention curve of the loess. The results showed that an alternative approach using a previously wetted filter paper could fruitfully be used with suction values fairly compatible with the HCT measurements.
\end{abstract}

The water retention curve obtained exhibited a peculiar form with no hysteresis observed around the natural water content $(14.4 \%)$ and two hysteresis loops on both the wet and dry sides of the curve. This zone with no hysteresis is supposed to correspond to the natural variations of the water content under seasonal changes, providing a range of natural suction between 20 and $80 \mathrm{kPa}$ that should obviously checked by in-situ measurements. The loess microstructure was investigated by using scanning electron microscope and mercury intrusion porosimetry. It appeared that the clay fraction $(16 \%)$ was not uniformly distributed with some areas composed of clean grains and a well graded corresponding inter-grains pore population. Conversely, the clay aggregations define a smaller sized porosity. The calculation of a water retention curve derived from the pore size distribution curve showed that water retention is governed by capillarity in the largest pores between clean grains whereas clay adsorption becomes dominant in smallest pores, a zone where the microstructure is sensitive to change in water content.

\section{INTRODUCTION}

Widespread aeolian loess deposits are located in Northern France (Antoine et al. 2003, Cui et al. 2004, Delage et al. 2005). In most areas, they are naturally unsaturated and characterised by satisfactory geotechnical properties with no particular problematic behaviour. In some areas however, some layers of loess are characterised by a significant calcareous content, a higher porosity and a low plasticity. These features lead to a metastable structure that is strengthened by suction when the soil is partially saturated. Subsequent soil saturation may thus induce a loss of stability of the structure with relatively large volumetric deformations due to the collapse of the open structure of the soil. This collapse behaviour of loose unsaturated soils has been observed by many authors including Barden et al. (1973), Yudhbir (1982), Alonso et al. (1987), Cui et al. (2004), Delage et al. (2005), Hormdee (2008), Punrattanasin (2008), Yuan and Wang (2009). 
A geological survey of the area showed that collapsible loess layers are protected from the interactions with the atmosphere and from rain by shallow layers of higher clay content and density. Since water table appears to be deep enough (more than $5 \mathrm{~m}$ depth as observed during various excavation works), some of these deposits may remain unsaturated in spite of being located in a quite rainy region.

Stability problems must be considered when the collapsible layers become exposed to atmosphere and rain due to excavation. Up to now, the main concern has been met along the North line of the high speed train (TGV) that links Paris to Brussels and London, in cut areas where the line went through collapsible layers. Besides other reasons like for instance the presence of remaining trenches from World War I in the Somme Battle region, the collapse susceptibility of loess is thought to be one of the reasons of some instabilities observed along the line and described in Cui et al. (1995).

In this paper, an investigation of the water retention properties of an unsaturated natural loess of Northern France is presented. This study is part of a wider on-going research program (Cui et al. 2004, Delage et al., 2005, Yang et al., 2008) on the hydro-mechanical behaviour of the loess that is conducted in relation with the French Railways company (SNCF).

In spite of the impressive interest towards unsaturated soils developed in the last decades, relatively few data on natural unsaturated soils have been published up to now. The data presented in this work aim at completing existing data on the water retention properties of unsaturated soils by further investigating the peculiar hydraulic behaviour of this natural unsaturated loess.

Up to now, water retention properties have been more often investigated by using methods of controlling suction. Here, two methods of measuring suction, the filter paper method and the high capacity tensiometer (HCT), respectively, are used on intact samples in which the water content is varied. The filter paper method provides suction measurements between 0.01 and about $10 \mathrm{MPa}$ whereas the suction range coverd by HCT is between 0 and $1 \mathrm{MPa}$. The water retention curve obtained in this work is also interpreted by using microstructure data from scanning electron microscopy (SEM) and mercury intrusion pore size distribution measurements.

\section{The loess of Northern France}

Loess deposits in Northern France were formed under periglacial conditions during the Quaternary period (15 000- 25000 years BP). At that time of low sea level that preceded ice melting, seashores had a different shape than presently. The presence of a glaciar front at the North-West of the area and the temperature and pressure gradients induced in the atmosphere above the ice mass resulted in constant and strong North-West winds, typical of cold and arid steppic climates (Antoine 2002, 2003). Winds eroded the ground exposed in the area, now corresponding to the Channel, close to the ice front and transported silt sized particles that were further deposited on the sedimentary deposits in widespread cover deposits. The thickness of loess deposit in the area ranges between 3 and 8 metres with a relative homogeneity. Loess deposits are homogenous in terms of composition and structure when considering a given horizon. However, these characteristics may vary with depth depending on the geological depositional conditions.

Figure 1 shows that the loess deposits are located along the Channel seashore from Normandy up to the Brussels area. They also include the Paris area where they are known under the term of "Limon des plateaux" (East of Paris). In most cases, loess deposits are unsaturated, a 
favourable condition in terms of agricultural potential that explains the prosperous wheat cultures that are found in the Eastern Paris area. The Orly and Roissy CDG airports, respectively south and north of Paris, are also located on loess deposits (Audric 1973).

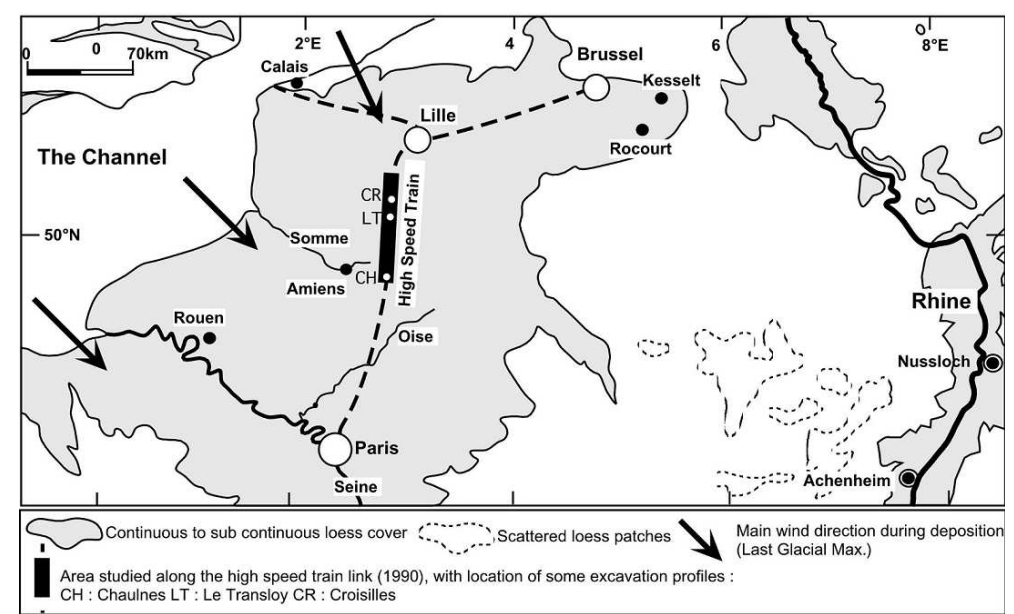

Figure 1. Extension of the Last Glacial loess in Northern France (after Antoine 2002)

As commented above, some loess layers are characterised by a low plasticity, a high porosity, a high calcareous content and an open structure that might give rise to collapse under wetting. These collapsible layers can be found in particular close to the city of Amiens in the Picardie region.

As quoted from Pecsi (1990) in Antoine (2002), "loess is not only dust accumulation". Diagenetic transformation includes clay illuviation from the surface that explains the higher density and plasticity and the lower permeability of the surface layer (about $20 \mathrm{~cm}$ in depth from the surface) that protects lower layers from rain water infiltration. Aeolian deposits are also affected by the subsequent chemical dissolution/re-precipitation of primary calcareous particles that change into a cementing agent. In this regard, the loess considered here falls into the category of cemented unsaturated soils with inter-grains bonding due to the combined action of calcareous cement and clay bonding. Whereas clay bonding is directly affected by changes in water content and suction, changes in calcareous bonding with suction is probably less significant. This combined effect has been investigated by various researchers including the theoretical considerations of Gens and Nova (1993) and the experimental investigations carried out on artificial soils by Leroueil and Barbosa (2000) and Koliji et al. (2010).

To obtain good quality specimen in a rather fragile material, intact block samples have been manually extracted using plastic cubic boxes of $300 \mathrm{~mm}$ side at different depths from a $5 \mathrm{~m}$ excavation in the area of Bapaume (Picardie). The geotechnical profile of the excavation is presented in Table 1.

\begin{tabular}{|c|c|c|c|c|c|c|c|c|c|}
\hline No. & $\begin{array}{c}\text { Depth } \\
(\mathrm{m})\end{array}$ & $w_{0}(\%)$ & $S_{r 0}$ & $\begin{array}{c}\rho_{s} \\
\left(\mathrm{Mg} / \mathrm{m}^{3}\right)\end{array}$ & $e_{0}$ & $w_{L}(\%)$ & $I_{P}$ & $\begin{array}{c}\mathrm{CaCO}_{3} \\
(\%)\end{array}$ & $\begin{array}{c}\text { Clay } \\
\text { content }(\%)\end{array}$ \\
\hline 1 & 1.0 & 14.4 & 0.44 & 2.67 & 0.85 & 28 & 9 & 6 & 16 \\
\hline 2 & 2.1 & 14.9 & 0.50 & 2.68 & 0.79 & 30 & 9 & 9 & 18 \\
\hline 3 & 3.3 & 21.2 & 0.91 & 2.66 & 0.63 & 30 & 9 & 5 & 25 \\
\hline 4 & 4.7 & 20.4 & 0.87 & 2.66 & 0.60 & 30 & 9 & 5 & 25 \\
\hline
\end{tabular}

Table 1. Geotechnical profile of the loess deposit 
One can observe that the plasticity index is constant along the profile and equal to 9. Upper layers are unsaturated (layer 1: $S_{r}=0.44$ at depth 1m, and layer 2: $S_{r}=0.50$ at depth $2.1 \mathrm{~m}$ ) compared to deeper layers that are closer to saturation. Layer $1(1 \mathrm{~m})$ is the loosest one $(e=$ $0.85, w=14.4 \%, S_{r}=44 \%, 6 \%$ carbonate content) and layer $2(2.1 \mathrm{~m})$ has the highest calcareous content $(9 \%)$. It is worth noting that, since the samples have been extracted at the end of the summer period, the water content and degree of saturation of the samples should correspond to relatively low values with respect to natural cycling changes. According to Cui et al. (2008) who monitored in situ suction and water content variations of a "Limons des plateaux" (an aeolian silt from same origin) located near Paris, shallow layers (upper than $50 \mathrm{~cm}$ depth) experienced suction changes between $10 \mathrm{kPa}$ (during winter) and $200 \mathrm{kPa}$ (during summer). Since this study concerns deeper layers protected by more clayey top layers, smaller suction variations are expected. The initial water content $(w=14.4 \%)$ value at $1 \mathrm{~m}$ depth should be smaller than the annual average value and the suction value (40 $\mathrm{kPa}$ ) close to the upper boundary.

The samples investigated here come from layer 1 that present the highest collapse potential. The grain size distribution of the sample investigated is given in Figure 2. The sand, silt and clay fractions are equal to 2,82 and $16 \%$ respectively. The dominant clay minerals are kaolinite, illite and interstratified illite-smectite (Karam 2006). The Casagrande classification of the loess is CL.

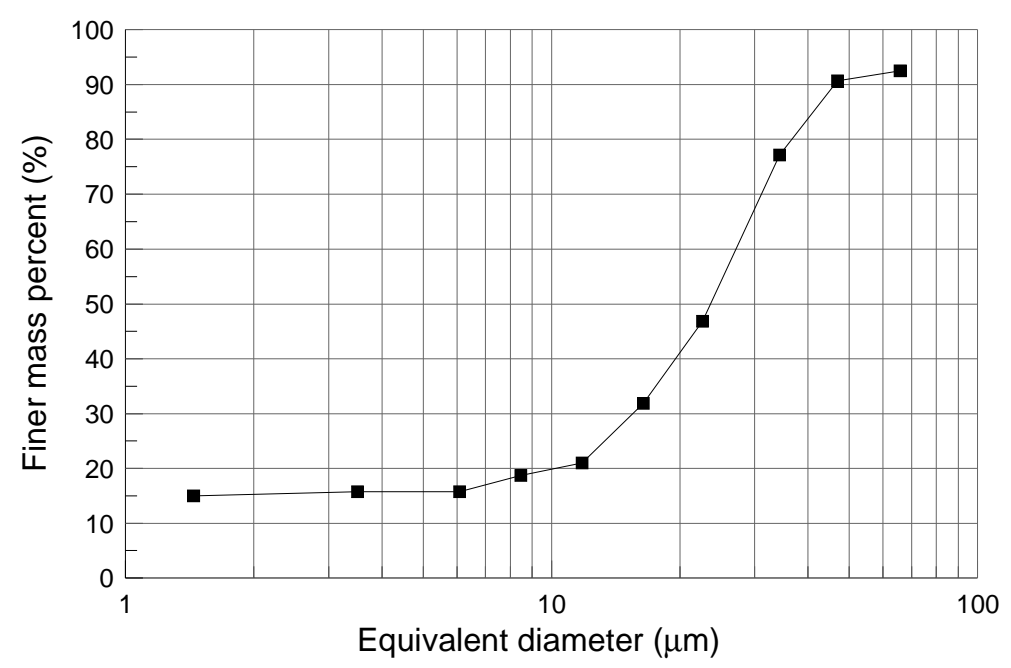

Figure 2. Grain size distribution of the loess from Bapaume (France)

\section{Filter paper measurements}

The filter paper method, developed several decades ago by Gardner (1937) to measure soil suction over a wide range, has been further investigated and used by many researchers (including Fawcett and Collis-George 1967, McQueen and Miller 1968, Al Khafaf and Hanks 1974, Hamblin 1981, Chandler and Gutierrez 1986, Houston et al. 1994, Swarbrick 1995, Bulut et al. 2002) prior to be standardized by the ASTM (2003, D 5298-03). Recent contributions also include papers by Patrick et al. (2007) and Kenton et al. (2008).

Parcevaux (1980) proposed an approach based on using an initially wet filter paper and provided the corresponding calibration curve. Since the "dry" approach (initially dry paper) recommended by ASTM and the "wet" one start from different initial water contents, hysteretic effects in the filter paper calibration curve are to be considered, as done by Leong et 
al. (2002) based on the compilation of data by several researchers (Fawcett and Collis-George 1967, Hamblin 1981, Greacen et al. 1987, Ridley 1995, Harrison and Blight 1998).

The equilibration time of both methods might be different when considering either a drying or a wetting process since the water infiltration rate depends on the partial permeability to liquid water that is largely influenced by the degree of saturation of water (both in sample and paper). Equilibration time should also vary with the amount of water to be transferred to reach equilibrium and hence depend on the suction to measure.

Figure 3 presents a compilation of filter paper calibration curves obtained on the Whatman 42 filter paper by various authors using either drying or wetting processes. Data below $1 \mathrm{MPa}$ (calibrated by techniques involving liquid transfers) concern matrix suction measurements whereas highest (total) suctions were determined with the vapour equilibrium technique. Quite a good agreement is observed between the data obtained independently by different authors with different techniques at different times. The data also provide a satisfactory insight into the hysteresis of the water retention curve of the filter paper.

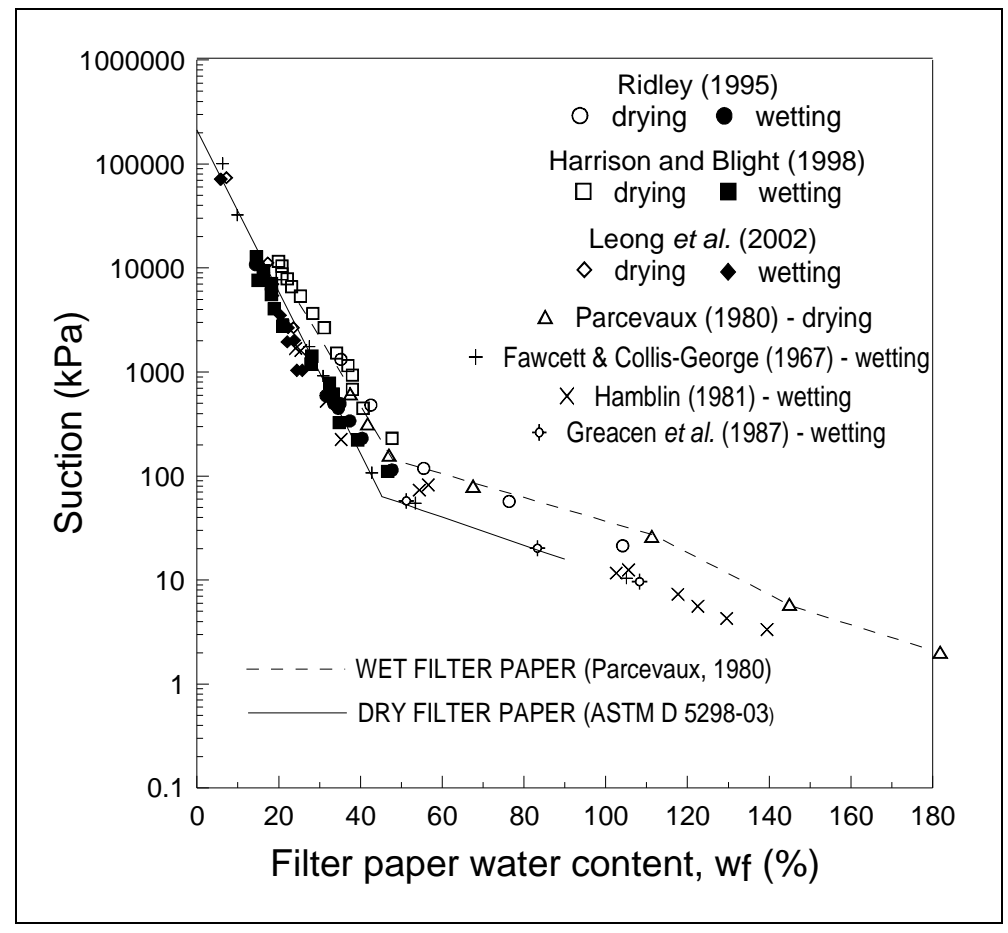

Figure 3. Calibration curves of Whatman No. 42 filter paper

In this work, a Whatman No. 42 filter paper was employed. The initial water content under ambient laboratory conditions of the Whatman No. 42 filter paper in original boxes is around $w=6.0 \%$ that corresponds to a suction of $29 \mathrm{MPa}$ that is almost the upper limit for measuring suction with the method (Marinho and Oliveira 2006). The testing procedure adopted here is described below.

Tests were performed on specimens of $70 \mathrm{~mm}$ diameter and $19 \mathrm{~mm}$ height. Specimens were carefully cut to get a surface as planar as possible thus ensuring a good contact with the filter paper piece. With respect to the ASTM procedure, it was preferred to place a set of three circular pieces of filter paper of $50 \mathrm{~mm}$ diameter between two pieces of soil so as to allow drainage on both faces of the paper and to ensure faster water transfer and better contact. The central piece of filter paper was cut smaller than the two other ones so as to keep it clean with no perturbation of the water mass measurement that would be caused by soil fragments. The overall set was then covered with paraffin wax, enveloped in a plastic film to avoid 
evaporation during the equilibration time and put in an insulated plastic box so as to reduce any temperature perturbation. After seven days, the set was opened, both soil samples and the central piece of filter paper were carefully weighed with a high precision balance $(1 / 10000 \mathrm{~g})$. Weighing was as quick as possible to minimize evaporation. Finally, suction was calculated from the filter paper water content using the appropriate calibration curve, depending upon the initial state of the filter paper.

Suction measurements were performed by using both the dry and wet filter paper methods to compare obtained values and equilibration times. Equilibration was monitored by weighing the filter paper at various periods of time varying from 1 to 12 days.

Samples were prepared starting from the natural water content $(w=14.4 \%)$ after either drying or wetting stages. Drying was performed by allowing evaporation of the sample under laboratory conditions for periods of time comprised between 1 and 4 hours. Wetting was achieved by adding small quantities of water to the soil sample. To do so, a piece of filter paper was placed on top of the sample and water drops were uniformly distributed over the surface using a syringe in order to ensure homogeneous wetting. Once the target water content was reached, a new filter paper was placed and the measurement was restarted. Target water contents were checked by weighing the samples while minimizing evaporation. The time period necessary to ensure a uniform water distribution within the sample has been estimated by using tensiometer measurements. Once suction was stabilized, water was assumed to be uniformly distributed within the soil matrix. The maximum equilibration time was estimated to 4 hours for both drying and wetting processes. The target values of water content were the following: $w=23.8,13.3,7.9$ and $7.2 \%$.

\section{The high capacity tensiometer}

Suction measurements by a home made high capacity tensiometer (CERMES HCT) based on the principle proposed by Ridley and Burland $(1993,1995)$ and already described in Mantho (2005) and Cui et al. (2008) were compared to those obtained by the filter paper technique. The suction values obtained by both methods were then used to determine the water retention curve of the loess.

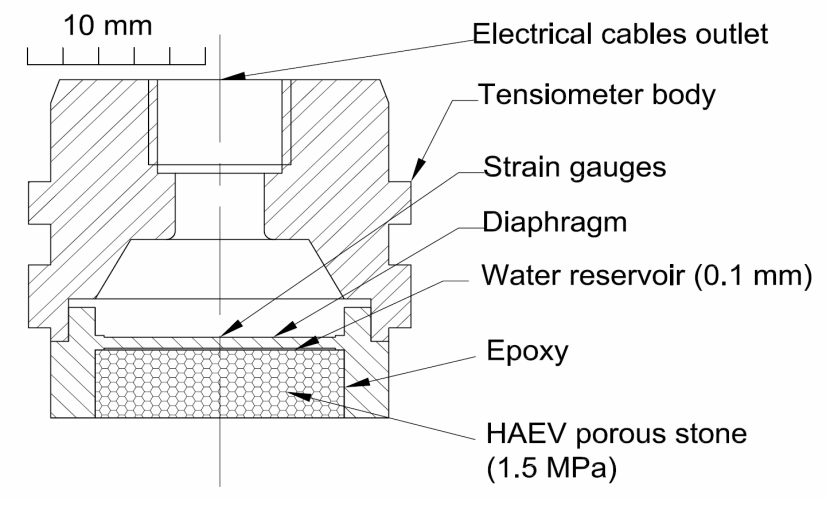

Figure 4. CERMES high capacity tensiometer (Cui et al. 2008)

As seen in Figure 4, the CERMES HCT is an integral strain gauge tensiometer (Tarantino 2004, Delage et al. 2008) composed of a porous high air entry value (1.5 MPa) ceramic disk with strain gauges glued to a metallic diaphragm and a water reservoir of $0.1 \mathrm{~mm}$ thickness. The HCT allows suction measurements ranging from 0 to about $1 \mathrm{MPa}$. As suggested by 
Tarantino and Mongiovi (2001), the HCT has first been saturated at a $4 \mathrm{MPa}$ positive water pressure to get rid of any air trapped in the system. Mantho (2005) proposed to resubmit the tensiometer to a water pressure of $2 \mathrm{MPa}$ after each cavitation of the water contained in the tensiometer reservoir. Performing such cycles of cavitation - saturation is suggested to improve the tensiometer performance in terms of range of measurement (Mantho, 2005) and measurement duration (Tarantino and Mongiovi 2001).

As seen in Figure 5, the HCT was inserted in the base of a modified oedometer cell already used to perform oedometer compression tests with suction measurements (Delage et al. 2008, Tarantino and De Col 2008). The oedometer base was placed on a precision balance to register weight changes with time. A loess specimen of $70 \mathrm{~mm}$ diameter and $19 \mathrm{~mm}$ height was inserted into a metallic ring and placed over the oedometer base. In order to improve the contact between the tensiometer and the soil sample and thus to avoid early cavitation, a fine layer of slurry made from the tested soil was placed on the tensiometer surface. To the same aim, a vertical stress of $1.5 \mathrm{kPa}$ corresponding to the piston weight has been applied to the sample. The vertical settlement induced by the piston is smaller than $0.04 \%$ and remains within the domain of elastic behaviour.

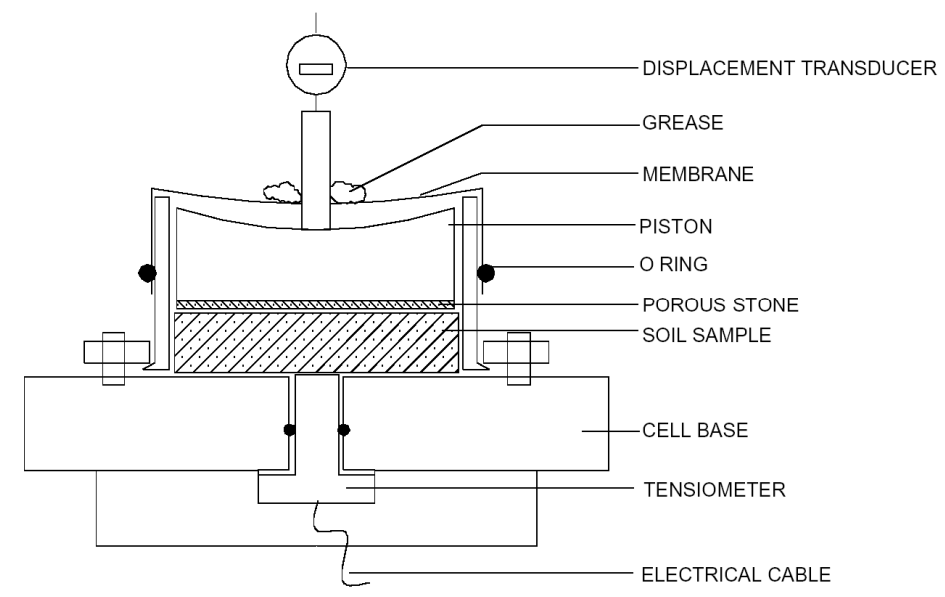

Figure 5. HCT measurement inside an oedometer cell (Delage et al. 2008)

Like in the filter paper test, the wetting process was carried out by removing the oedometer piston (loading-unloading cycles do not imply significant volume changes) and by carefully dropping, with a syringe, small amounts of water over a filter paper in contact with the upper face of the sample. Once the desired water content reached, the piston was placed back and a membrane was installed so as to avoid evaporation as shown in Figure 5. The drying process was performed by free drying after having removed the oedometer piston. Once the desired water content reached (indicated by the balance measurement), water content equilibration was waited for after placement of both piston and membrane. After each change in water content, an equilibration time of 1 hour was waited for before measuring suction with the HCT.

\section{RESULTS AND DISCUSSIONS}

\section{Filter paper measurements}

Filter paper measurements were performed on four samples, starting from different water contents $(w=23.8,13.3,7.9$ and 7.2\%). Suction measures for both dry and wet filter paper methods are presented later together with the overall experimental data. As an illustration of the suction equilibration process between the sample and the filter paper, Figure 6 presents the 
evolution in suction measurement with time for the test corresponding to an initial water content $w=13.3 \%$. Each point corresponds to the measurement of the water content of the filter paper at a given time (between 1 and 12 days) once the contact between the filter paper and the soil has been ensured. After each weighing, a new filter paper was inserted into the soil sample to perform the subsequent measurement. In the dry method, the filter paper extracted water from the soil whereas it released water to the soil in the wet method. The corresponding wetting or drying branch of the filter paper calibration curve (Figure 3) was used accordingly.

Figure 6 shows that monotonic changes in water content are observed. The two curves tend to converge with a difference in final suction value around $0.5 \mathrm{kPa}$ after 7 days, providing an average final value of $46.5 \mathrm{kPa}$. In all tests, water transfers tend to stabilize after a few days, generally before the seven days period recommended by ASTM.

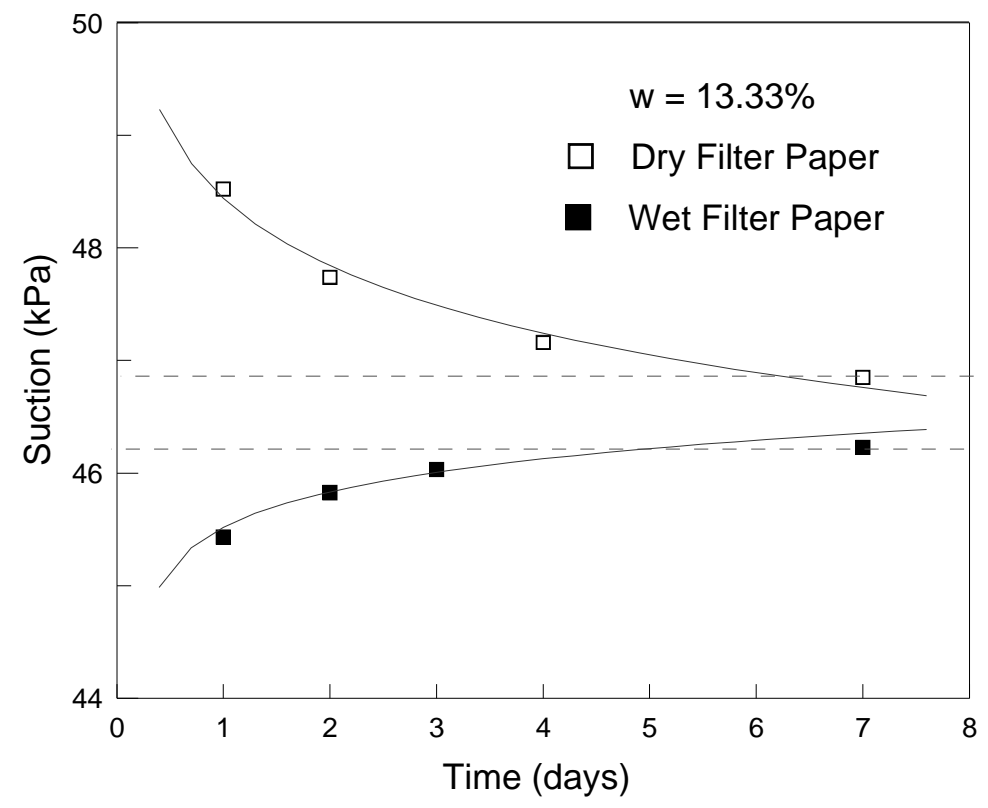

Figure 6. Evolution of suction measurement with time obtained by the filter paper techniques

An overall good agreement between the results obtained by the two protocols (wet and dry paper) is observed. It has also been checked that the water exchanges due to the presence of the filter paper itself had a negligible influence on the measured suction. This influence is estimated for all tests in Table 2 in which the ratio $\Delta M_{w}^{F P} / M_{w}^{\text {soil }}$ between the change of mass of water in the filter paper $\left(\Delta M^{F P}{ }_{w}\right)$ and the total mass of water in the soil sample $\left(M^{s o i l}{ }_{w}\right)$ is given at all final water contents for both techniques. Obtained data shows that water exchanges are quite small, confirming that the filter paper does not significantly affect the hydric state of the sample. This confirms that both protocols provide comparable results in terms of measured values.

\begin{tabular}{|c|c|c|}
\hline$w_{\mathrm{i}}(\%)$ & $\begin{array}{c}\text { Wet Filter } \\
\text { Paper }\end{array}$ & $\begin{array}{c}\text { Dry Filter } \\
\text { Paper }\end{array}$ \\
\hline 23.8 & $0.74 \% \circ$ & $2.04 \% o$ \\
\hline 13.33 & $2.86 \%$ o & $1.93 \%$ o \\
\hline 7.88 & $9.89 \% o$ & $2.58 \% o$ \\
\hline 7.19 & $10.02 \% o$ & $2.15 \% o$ \\
\hline
\end{tabular}

Table 2. Ratio of water exchange between filter paper and soil 
The water retention properties of the natural loess obtained with both dry and wet filter paper methods are presented in Figure 7 in a suction/water content diagram. The values of the degree of saturation are also presented in the top $x$ axis under the hypotesis of no volume change, showing that a degree of saturation of 1 theoretically corresponds to a water content of $w=31.8 \%$. Since the degree of saturation under the lowest $3 \mathrm{kPa}$ suction is $w=26.5 \%$, it is very probable the sample not to be fully saturated when put under zero suction by infiltrating liquid water. However, this has not been possible since the material became very soft and difficult to handle in such conditions.

The data presented in Figure 7a) were obtained along two hydric paths imposed to two distinct specimens starting from the same initial point $(w=13.2 \%, s=35.8 \mathrm{kPa})$.

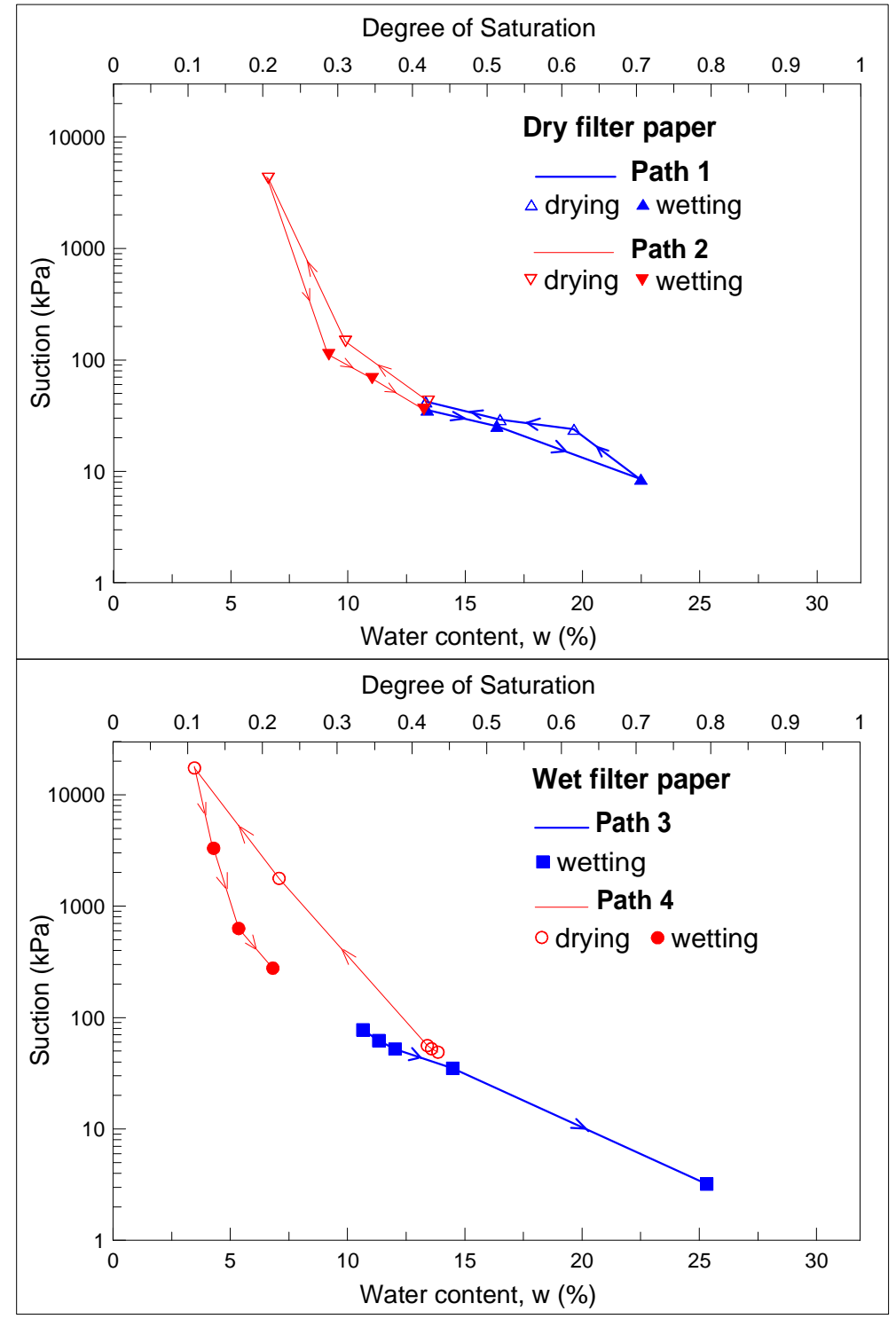

Figure 7. Hydraulic paths by the filter paper technique on Bapaume loess

A wetting path was imposed with values of water content successively equal to $16.5 \%$ and $22.5 \%$ (the last value corresponding to $s=8.6 \mathrm{kPa}$ and $S_{r}=0.71$ ). The specimen was subsequently dried at $w=19.7 \%\left(s=23.9 \mathrm{kPa}, S_{r}=0.60\right)$ and wetted back to a point that appeared to be very close to the initial one at $w=13.3 \%\left(s=42.2 \mathrm{kPa}, S_{r}=0.41\right)$. Whereas some hysteresis is observed above $w=16.2 \%$, hysteresis becomes quite slight between $w=14$ and $w=16 \%$ with two close parallel sections of the water retention curve. Starting from the 
same initial point ( $w=13.4 \%, s=42.3$ ), another specimen was dried in 3 steps down to $w=$ $6.6 \%\left(s=4250 \mathrm{kPa}, S_{r}=0.20\right)$ prior to be wetted back in 3 steps up to $w=13.2 \%$ (s $=35.8$ $\left.\mathrm{kPa}, S_{r}=0.41\right)$ to finally reach a point very close to the initial state. Again, a small hysteresis is observed along the cycle. The data of the test carried out with the wet filter technique are presented in Figure 7b. A drying phase was imposed in two steps down to a water content $w=$ $3.5 \%\left(s=17.3 \mathrm{MPa}, S_{r}=0.11\right)$ prior to rewetting the specimen in 3 steps up to $w=6.8 \%(s=$ $\left.277 \mathrm{kPa}, S_{r}=0.21\right)$, a point at which the test was ended. The other path starting by an unplanned drying phase down to $w=10.8 \%\left(s=78 \mathrm{kPa}, S_{r}=0.33\right)$ followed by a wetting phase up to $w=25.6 \%\left(s=3.2 \mathrm{kPa}, S_{r}=0.79\right)$.

All the points obtained with both the dry and wet filter paper methods are presented in Figure 8. The figure shows excellent agreement between the results obtained by the two methods on 4 different samples, showing both the quality of the technique and the homogeneity of the samples.

\section{HCT measurements}

The water retention curve of the intact loess from Bapaume was obtained by performing various hydric paths and by measuring suction using on one hand the HCT and on the other hand the wet and the dry filter paper methods described above. Hydric paths were started from the natural loess water content of $14.2 \%$ that corresponds to an initial degree of saturation of 0.44 and a suction of $40 \mathrm{kPa}$ as measured by the filter paper (wet or dry).

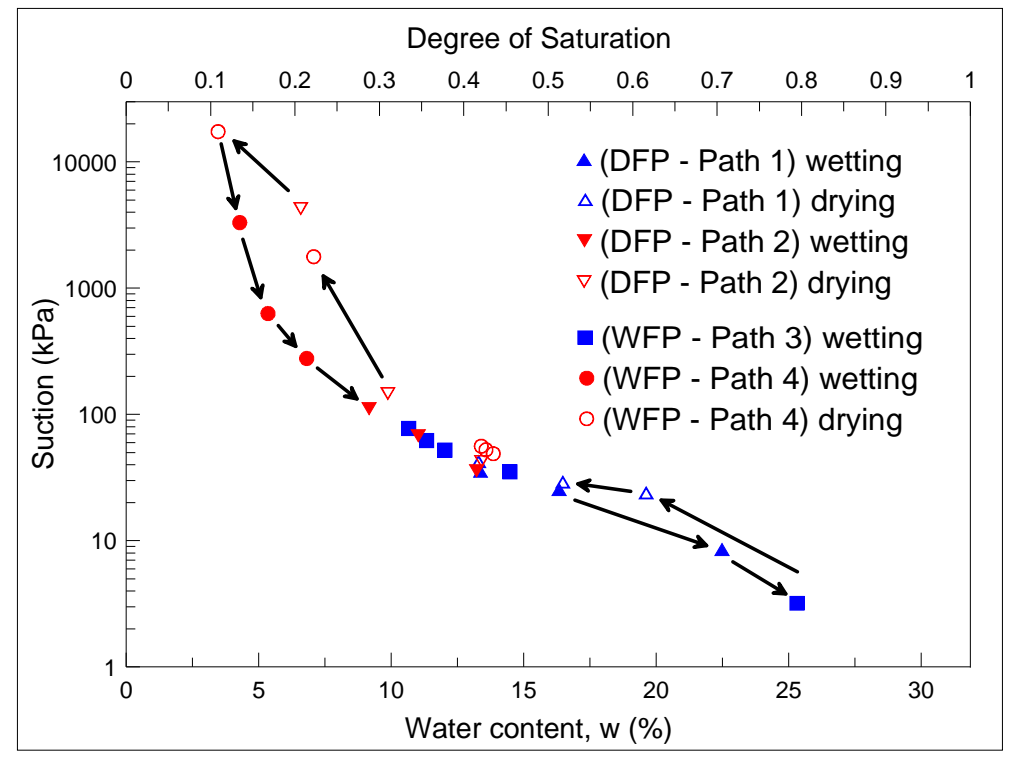

Figure 8. Summary of all the data obtained with both the wet and dry filter paper methods

As commented above, HCT measurements were conducted in an oedometer cell (see Figure 5). Some examples of the response of the HCT with time along both a wetting (top) and a drying phase (bottom) are presented in Figure 9. 


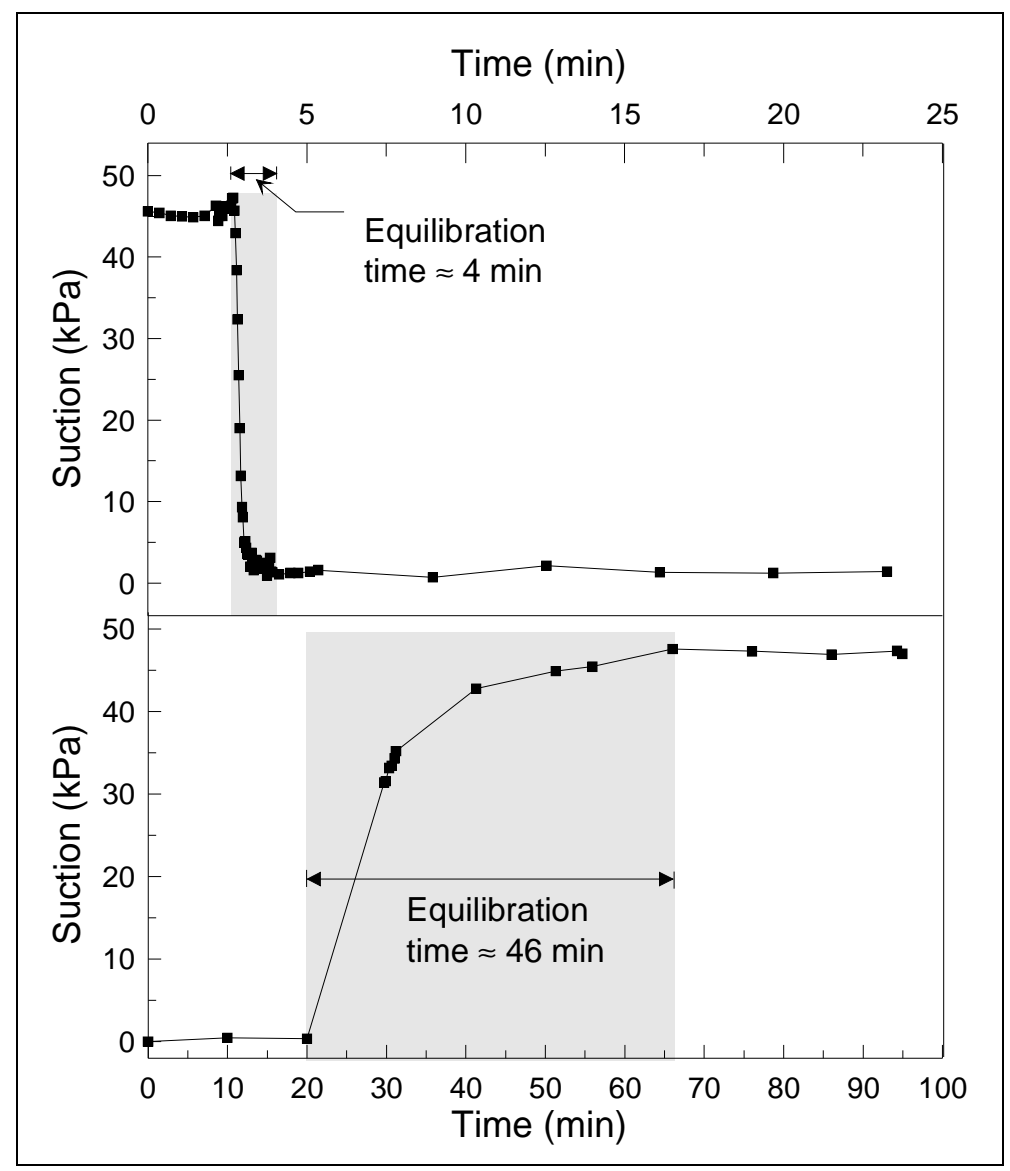

Figure 9. Response of the HCT with time for both a wetting (top) and a drying (bottom) path

HCT readings in the wetting phase (suction reduced from $45 \mathrm{kPa}$ to $0 \mathrm{kPa}$ ) indicate that quite a short period of time comprised between 3 and $10 \mathrm{~min}$ was necessary to reach equilibrium. For a drying phase (suction increase from zero to $45 \mathrm{kPa}$ ), a longer period of time comprised between $30 \mathrm{mn}$ and $1 \mathrm{~h}$ was observed. Longer equilibration times were observed with higher suctions, in accordance with previous results in the literature (Ridley and Burland 1999, Delage et al. 2008). The difference in kinetics observed in Figure 9 is due to a faster liquid transfer in the case of wetting compared to phase change and vapour transfer (evaporation) in the case of drying. It also corresponds to the differences observed in permeability changes during drying and wetting processes, favourable to faster equilibrium during wetting. Note that the wettest states obtained correspond to a water content $w=27.0 \%\left(S_{r}=0.84\right)$ with a calculated water content at saturation equal to $w=31.9 \%$ (assuming a rigid skeleton). It indeed appeared practically impossible to wet samples at higher water content than $27.0 \%$ with the technique adopted here since further wetting made the samples quite soft, sticky and impossible to handle.

Four hydraulic paths ( 2 wetting and 2 drying paths) carried out on 4 distinct samples were performed using the HCT technique in the oedometer (Figure 10). As seen in the figure, the maximum suction measured was equal to $898 \mathrm{kPa}$, a suction value at which the HCT satisfactorily behaved. An advantage of the technique is that there is neither any manipulation nor any weighing of the sample making it easier to obtain a large number of measurement points. The drying and wetting paths presented on top of Figure 10 (paths 1 and 2) again exhibit a rather slight hysteresis with parallel wetting and drying curves close one to the other, particularly in the area of the initial water content. A quite good correspondence is observed between the data that come from two distinct samples. Path 3 presented in the bottom graph exhibits a trend similar to the previous paths in the same area with a closed cycle ending at a 
point with $w=14.5 \%$ and $s=23 \mathrm{kPa}$. The wetting stage of path 4 also lies close to that obtained during path 3 on another sample.

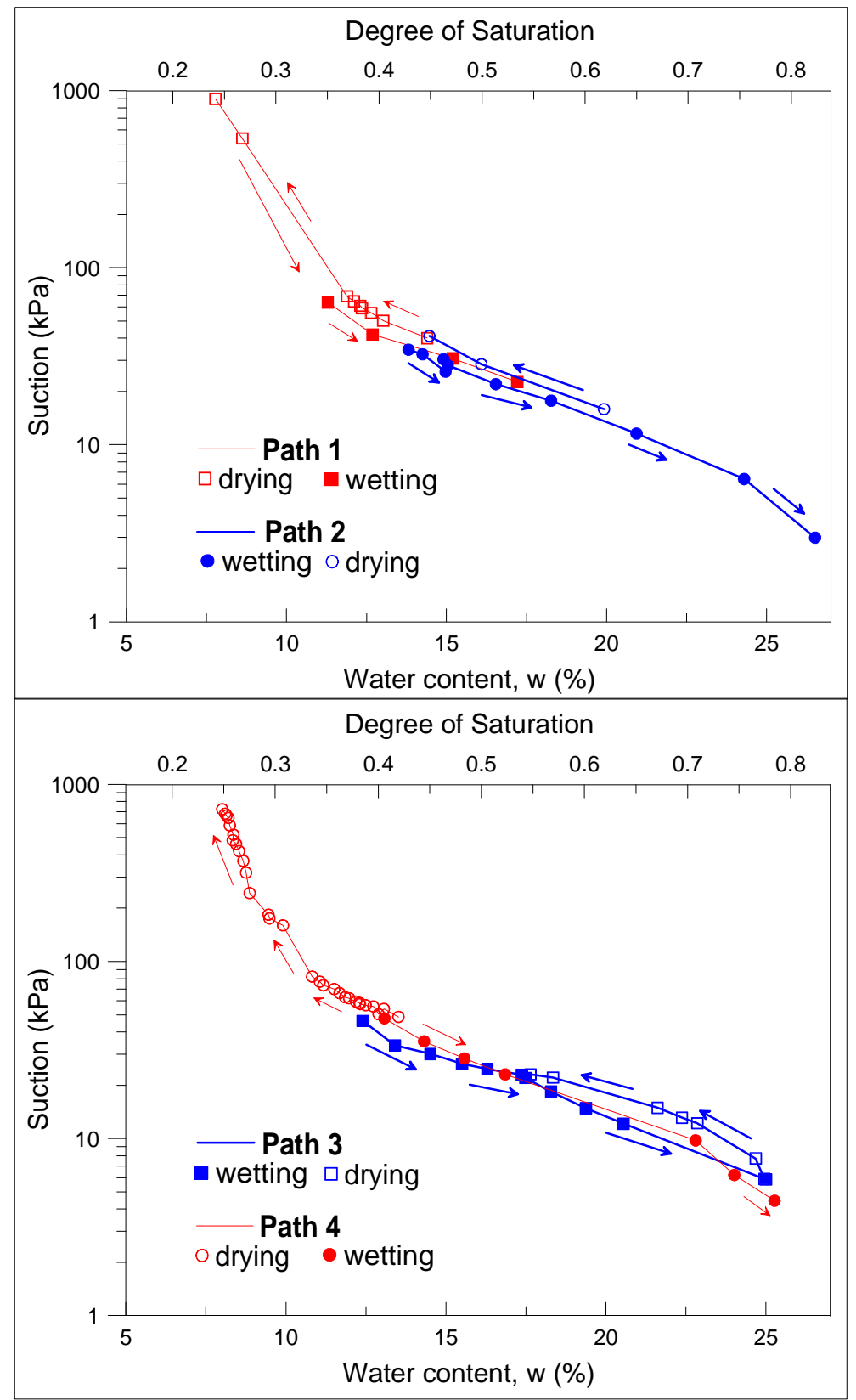

Figure 10. Hydraulic paths by the tensiometer on Bapaume loess

\section{Microstructural observation}

The microstructure of the intact loess has been investigated by using both mercury intrusion pore size distribution (PSD) measurements and scanning electron microscope (SEM) observations. Both techniques must be carried out on dry samples. To preserve the microstructure during dehydration, samples were dehydrated by freeze drying (Delage et al. 1982). To ensure instantaneous freezing, small sticks were plunged in liquid nitrogen ($\left.196^{\circ} \mathrm{C}\right)$ that was frozen down to its cooling point $\left(-210^{\circ} \mathrm{C}\right)$ by applying vacuum to nitrogen prior to sample immersion (Delage et al. 2006). In such conditions, the heat quantity brought by the small soil sticks when plunged into nitrogen is not enough to heat nitrogen up to its boiling point. The water transfer occurs in liquid phase and is not slowed down by nitrogen bubbling as when directly plunging sample in liquid nitrogen. The heat transfer during 
freezing is instantaneous and generates amorphous ice with no volume expansion (Delage and Pellerin 1984).

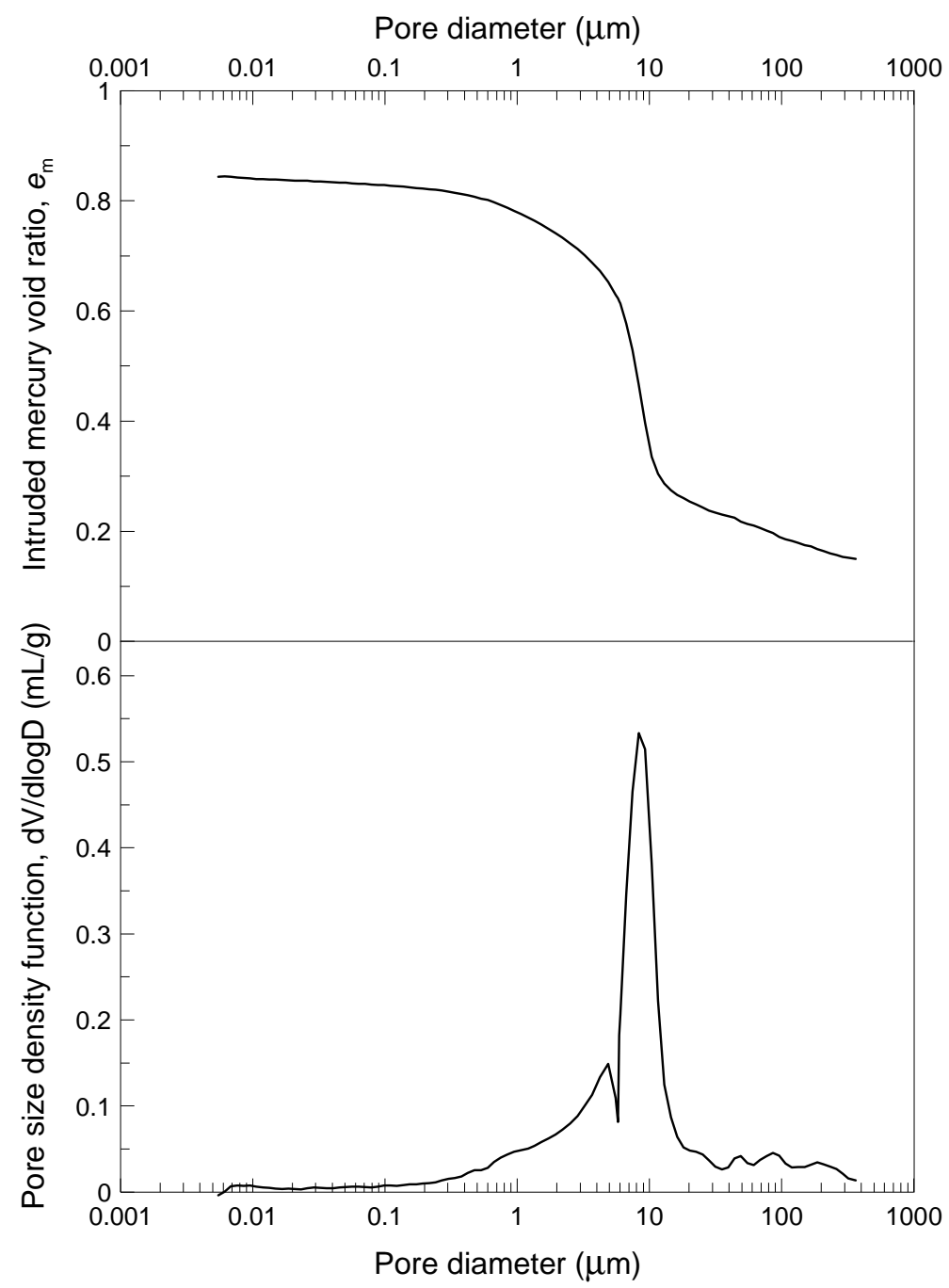

Figure 11. Pore size distribution of Bapaume loess

Figure 11 presents the PSD curve of an intact sample of Bapaume loess in a diagram in which the intruded pore volume ( $y$ axis) is expressed in terms of a void ratio $e_{\mathrm{m}}$, i.e. by using the ratio of the intruded volume divided by the volume of the solid phase $\left(V_{\mathrm{Hg}} / V_{s}\right)$. In the test presented, mercury intrusion was started at a pressure of $3.4 \mathrm{kPa}(0.033 \mathrm{~atm})$ quite below the atmospheric pressure, corresponding to an equivalent entrance pore diameter of $363 \mu \mathrm{m}$. Actually, the total volume of intruded mercury $\left(e_{m}=0.70\right)$ appeared to be smaller than the total pore volume of the sample determined in a standard way (void ratio $e=0.85$ ). This difference may be due to the fact that, as seen by visual inspection, pores larger than $363 \mu \mathrm{m}$ diameter exist in the loess. Since the clay fraction of the loess is small and based on previous experience on Eastern Canada sensitive clays (Delage and Lefebvre 1984, Delage 2010), compacted low plasticity silt (Delage et al. 1996) and compacted kaolinite (Sridharan et al. 1971), it is believed that most of the pore volume is intruded when reaching the maximum mercury pressure (200 MPa) (soils that are not fully intruded by mercury at $200 \mathrm{MPa}$ often contain a significant fraction of smectite as observed by Lloret et al. 2003 and Delage et al. 2006). This statement is also in agreement with the fact that the PSD curve becomes tangent to horizontal in the area of smallest pores whereas it remains inclined in that of largest pores, showing that pores with an entrance diameter larger than $0.363 \mathrm{~mm}$ probably exist. For this 
reason, the intrusion curve has been fitted with the total pore volume in the area of small pores.

The data of Figure 11 show the existence of a main pore population with an average entrance diameter of $8.3 \mu \mathrm{m}$ that represent $49 \%$ of the total porosity (if taken between 3 and $11 \mu \mathrm{m}$ ). Smaller pores correspond to $15 \%$, whereas largest pores represent $36 \%$ of the total porosity. The inclined linear section of the curve in the largest pores area indicates a poorly graded PSD, with some largest pores of $0.5 \mathrm{~mm}$ diameter that are visually observable, as commented before.

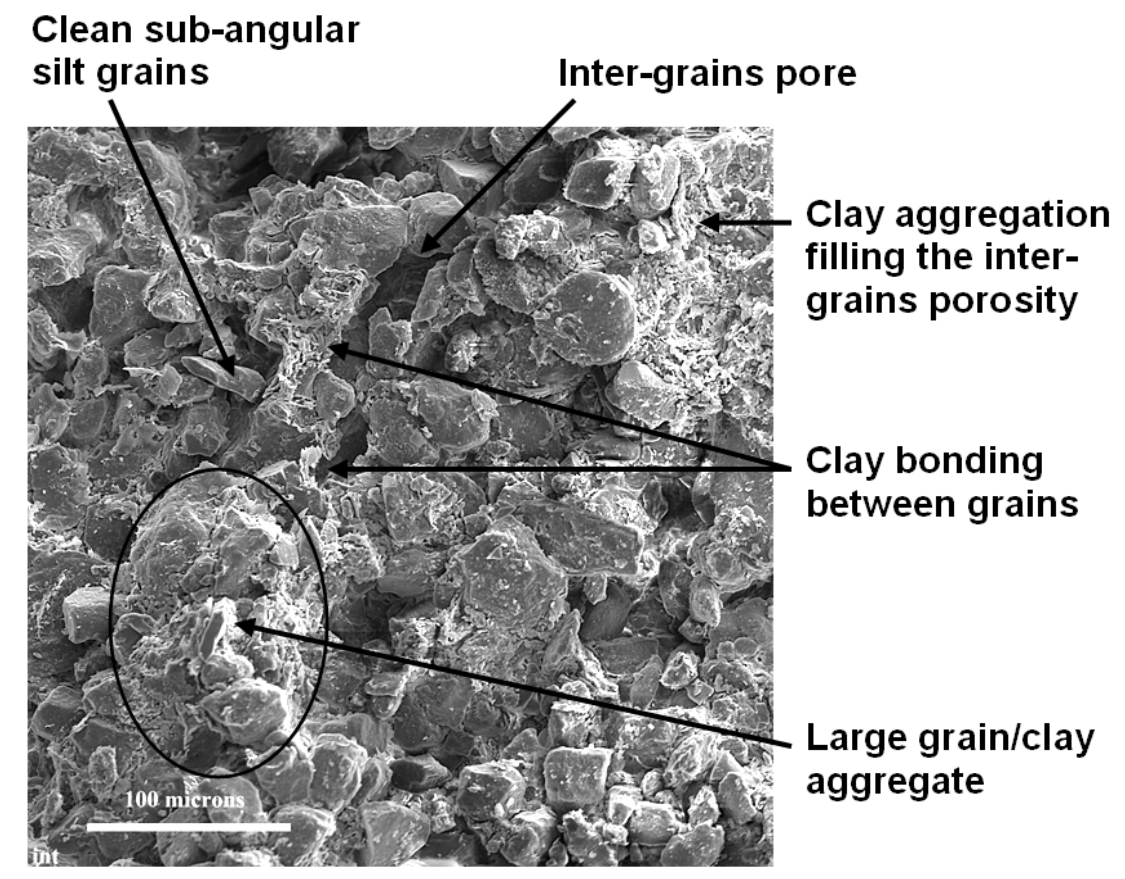

a)

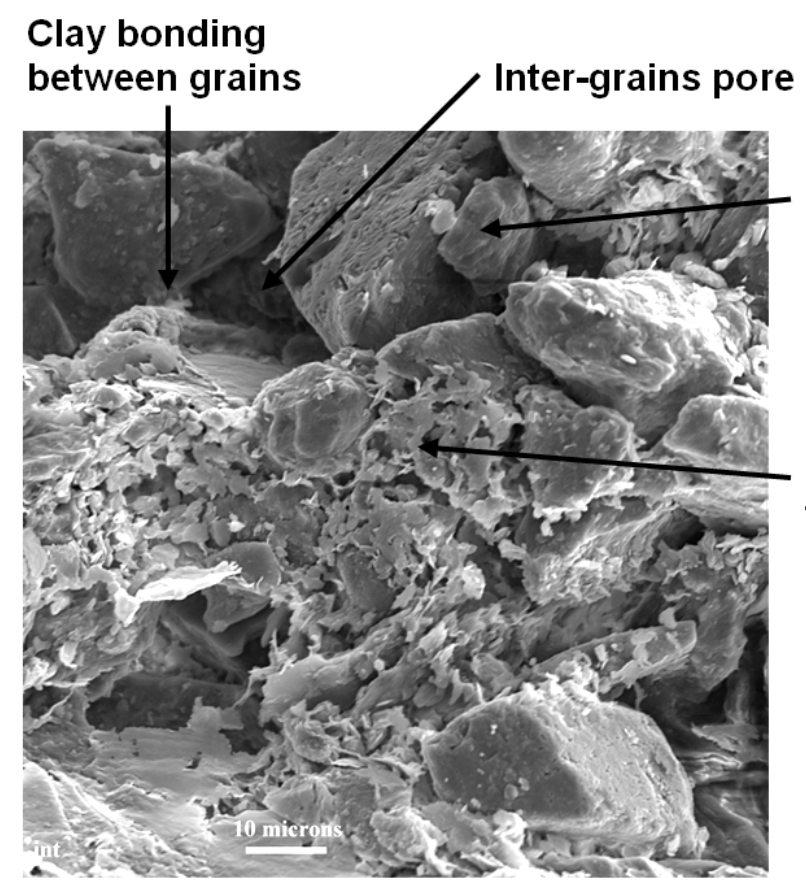

Clean sub-angular silt grain

Clay aggregation filling the intergrains porosity

b) 


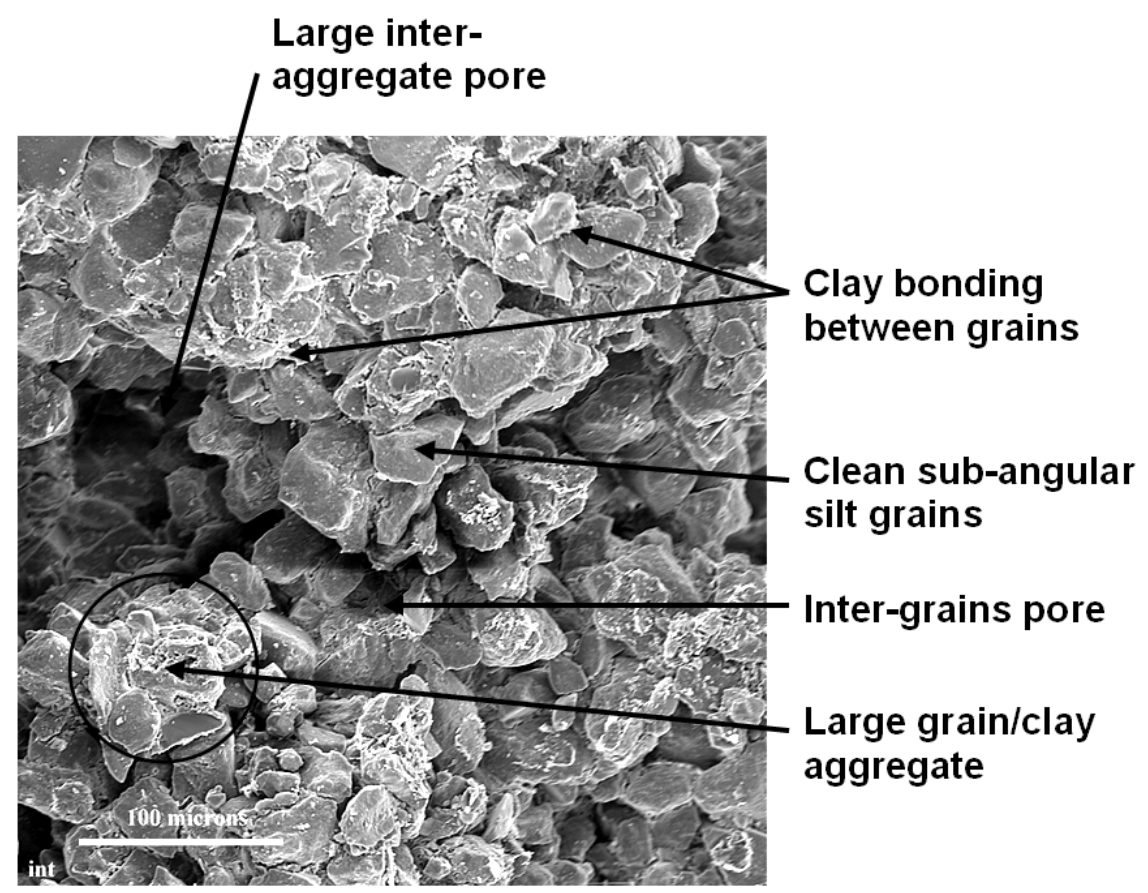

c)

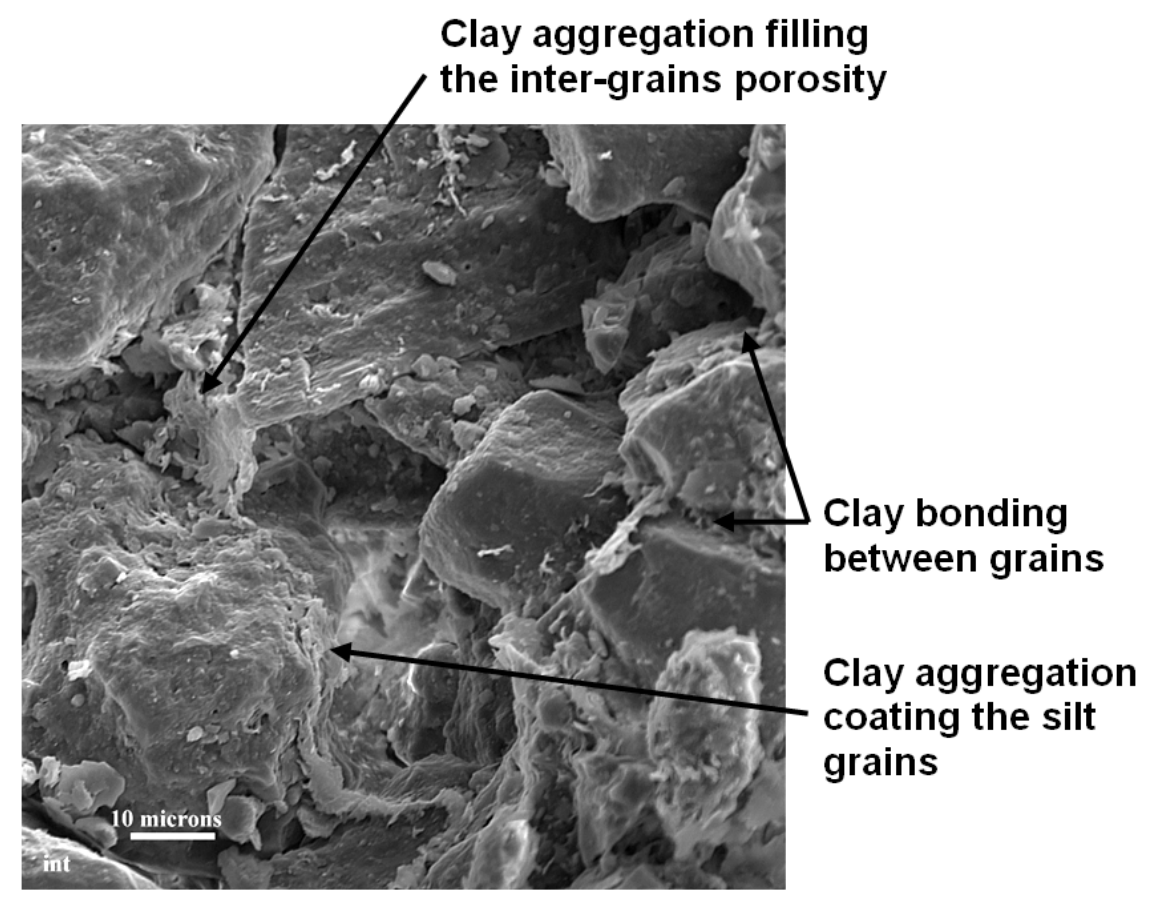

(d)

Figure 12. SEM observations of the Bapaume loess

SEM observation was carried out on surfaces that were obtained by fracturing the frozen soil sticks prior to placing them under vacuum in the freeze dryer apparatus in which ice is sublimated (Delage et al. 1982). In such condition, the observation surface is not defined, as in ESEM, by any weakness plane of the wet soil microstructure and no deformation occurs when fracturing. The observation surface is plane indeed, well defined and it does cross the various levels of microstructure, allowing better observation. Examination of the SEM photos presented in Figure 12 at two magnitudes (see the bars giving lengths in micrometers) clearly show (Figure 12a, Figure 12c) a dominant proportion of subangular silt grains with diameters 
of several tens of micrometers. The figure also shows that the clay fraction is not regularly scattered among the grains. Whereas some grains are quite clean, some others appear to be strongly linked together by clay aggregations that seem to be firmly stuck to the grains. The figure also shows a "grain/clay aggregate" made up of various grains completely embedded in a clay matrix. Clay aggregations locally fill the inter-grains porosity. This is observed in more details in Figure 12b in which clay aggregations appear to be frankly cut by the freeze fractured observation plane. Here also, clean grains stuck together by clay aggregations (Figure 12d) are visible with also some clay bridges linking clean grains together. Observation of the SEM photos suggest that the resistance of the microstructure should not be homogeneous based on the irregular position of the clay aggregations. Clearly, collapse under wetting should occur by the densification of the areas where grains are clean with large pores around them. The zones in which the porosity is filled by clay aggregation should be more resistant and locally less sensitive to collapse.

SEM observations help to interpret the PSD curve of Figure 11 in more details. A large interaggregate pore with a diameter close to $100 \mu \mathrm{m}$ that belongs to the poorly graded large pore population evidenced by the PSD curve of Figure 11 is observed in Figure 12c. Figure 12b shows an inter-grain pore of a diameter close to $10 \mu \mathrm{m}$, compatible with the main pore population with a $8.3 \mu \mathrm{m}$ average diameter. Inspection of the clay aggregations (Figure 12b) shows that the largest intra-aggregate pores should be close to 1-2 $\mu \mathrm{m}$, in accordance with the smallest pore population of Figure 11.

The process of mercury penetration can hence be described based on the SEM photos. In a first stage at lowest pressures, mercury penetrates the largest inter-grains porosity and embeds all clean grains prior to penetrate the smallest clay intra-aggregate porosity. Once the pressure corresponding to $2-3 \mu \mathrm{m}$ is reached, the penetration of mercury in the clay aggregates starts.

\section{Discussion}

All data obtained with the two filter paper methods and the HCT technique are now plotted in Figure 13 together with a curve obtained from the PSD curve that will be further commented later. The filter paper measurements performed to study the changes in suction with time from different water contents $(w=23.8,13.3,7.9$ and 7.2\%) are also presented and referred to as "DFP/WFP equilibration time data" (Dry Filter Paper/Wet Filter Paper). The data show a good global agreement between the various methods used on distinct samples. It confirms the validity and the quality of both suction measurements and highlights the homogeneity of the various samples tested. The results provide a detailed description of the water retention curve of the natural loess.

Compared to existing published data in which the hysteresis of water retention curves (Hillel 1971, Pham et al. 2005) is clearly apparent (see for instance recent experimental data concerning natural soils from Konyai et al. 2006 in a saline sandy loam, Le et al. 2008 in Boom clay, Askarinejad et al. 2011 in a natural silty sand and Vasquez et al. 2011 in a red clay of high plasticity), the water retention curve obtained here exhibits quite a particular shape, with no apparent hysteresis observed in the area of the initial water content (between $w$ $=11.0$ and $16.0 \%$ ). With an initial natural water content close to $w=14.4 \%$, one can conclude that little hysteresis affects the soil when submitted to change in water content imposed by climatic changes around this value. Under this hypothesis, water changes could be included between $w=11.0 \%$ in summer and $w=16.0 \%$ in winter with corresponding suctions of 20 and $80 \mathrm{kPa}$ respectively. These ranges would of course need to be checked by direct in-situ suction measurements. Conversely, hysteresis appears to be quite apparent on both the wet ( $w$ $>16 \%)$ and dry $(w<10 \%)$ sides of the curve. 


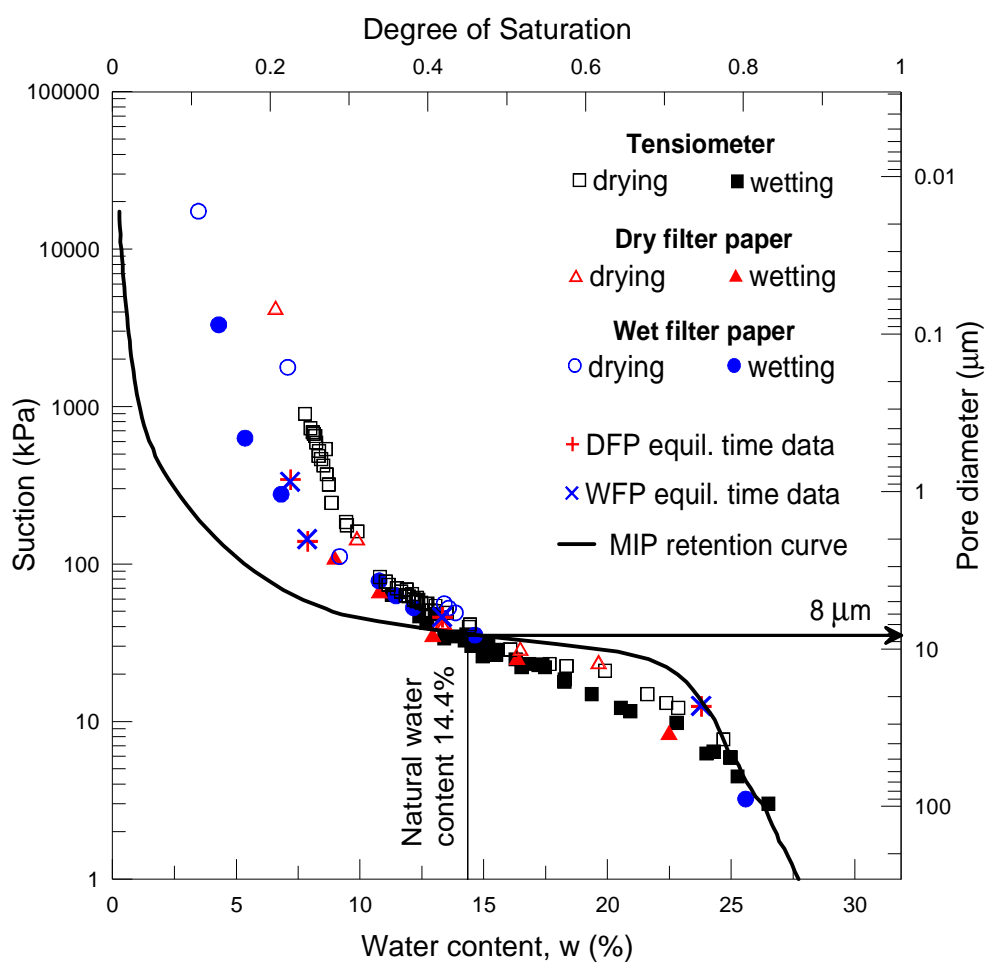

Figure 13. Retention curve of the intact loess from the different approaches used

It is well known that there are close links between the water retention curve of a soil and its pore size distribution, provided water-soil interactions in the soil are mainly governed by capillarity. Indeed, mercury intrusion porosimetry (MIP) is currently used in petroleum engineering to characterize more rapidly the capillary curve (another name of the water retention curve) of reservoir rocks like chalks or sandstones (with negligible clay fraction). In this regard, the mercury intrusion process, in which a non wetting fluid (liquid mercury) is penetrating a porous medium full of a wetting fluid (mercury vapour under vacuum) is assimilated to a drying process. In other words, the pore size distribution cumulative curve can be used to extrapolate a drying curve (see for instance Prapaharan et al. 1985, Delage et al. 1995, Romero 1999, Aung et al. 2001, Simms and Yanful 2001, 2002). To do so, one considers the Laplace's capillary equation applied to a capillary cylindrical tube (Jurin's law, sometimes called Wahsburn's equation) that is the base of MIP interpretation. Laplace's equation links the capillary pressure (difference in fluids pressure on both sides of a capillary meniscus) to the interfacial properties of the fluids-solid system together with the diameter of the cylindrical tube as follows:

$u_{n w}-u_{w}=\frac{4 T \cos \theta}{D}$

Eq. 1

in which:

- $\quad u_{n w}$ and $u_{w}$ are the pressure of the non wetting (mercury or air) and wetting (mercury vapour under vacuum or water) fluids respectively;

- $\quad T$ is the non-wetting-wetting surface tension (at $20^{\circ} \mathrm{C}, T_{w}=72.75 \times 10^{-3} \mathrm{~N} / \mathrm{m}$ for airwater interface and $T_{H g}=485 \times 10^{-3} \mathrm{~N} / \mathrm{m}$ for liquid mercury-vapour mercury interface); 
- $\theta$ is the wetting fluid/solid contact angle $\left(0^{\circ}\right.$ for water and $140^{\circ}$ for mercury in clays according to Diamond 1970).

Under the hypothesis of a cylindrical shape, an indirect estimation of the pore diameter can hence be obtained through Laplace's equation with the two fluids/solid systems, giving:

$$
D=\frac{4 T_{w}}{\left(u_{a}-u_{w}\right)}=-\frac{4 T_{H g} \cos \theta}{\left(u_{H g}-u_{V H g}\right)}
$$

where $u_{H g}$ and $u_{v H g}$ are the liquid mercury (non wetting fluid) and the vapour mercury (wetting fluid) pressures respectively. Matrix suction $\left(u_{a}-u_{w}\right)$ can then be related to the mercury intrusion pressure $\left(u_{H g}-u_{V H g}\right)$ as follows:

$$
u_{a}-u_{w}=-\frac{T_{w}}{T_{H g} \cos \theta}\left(u_{H g}-u_{V H g}\right) \approx 0.196\left(u_{H g}-u_{V H g}\right)
$$

A water retention curve can hence be extrapolated from the mercury intrusion curve by using Eq. 3.

The curve derived from the PSD curve plotted in Figure 13 (in which the entrance pore diameter from the MIP analysis are also plotted on the right $y$ axis) significantly differs from the drying branch of the water retention curve, particularly in the area of small pores. However, it should be noticed that the curve is exactly passing through the point at natural state. The correspondence is also better in the zone of largest pores, with however a bend in the PSD derived curve that is not observed in the WRC curve.

The differences between the WRC and curves derived from PSD have been discussed in the literature and for instance Simms and Yanful (2001, 2002) mentioned the possible effects of the pore trapping effect (mercury intrusion only gives the entrance pore radius thus somewhat surestimating the porous volume associated to the estimated diameter). There are other reasons why the two curves should not be the same in soils containing some clay fraction whereas they compare favourably in granular soils and rocks. Mainly, the microstructure of the former is sensitive to changes in water content whereas the latter have a stable microstructure at all water contents. This stable microstructure governs in a constant way the response of both mercury intrusion and water drainage, giving comparable results. The WRC of a fine-grained soil results from a microstructure that changes with the water content changes whereas the PSD curve is obtained at the microstructure that corresponds to the water content at which it has been performed. In this regard, the good correspondence observed at natural water content in Figure 13 is interesting.

Under the hypothesis of having water located in the smaller pores due to both capillary action and water adsorption on clay particles, all pores located in pores with a diameter $(8 \mu \mathrm{m})$ smaller than that corresponding to the natural water content $(14.4 \%)$ should be saturated whereas pores of higher diameter should be dry. Referring to SEM observations, this means that the largest porosity between clean grains should be dry whereas the clay aggregations should be water saturated. Then, the almost satisfactory correspondence observed on the right side of the drying curve concerns capillary effects in a dry granular assembly, compatible with observations in dry samples or sandstones.

On the left side of the natural water content, the significant difference between the curves concerns the saturated smaller porosity that is prone to significant microstructure changes under drying. On a compacted silt form the same aeolian origin, Delage et al. (1996) observed that drier samples were characterised by the coating of the clay particles along the grain 
surface, whereas in wetter samples, hydrated clay particles appeared to be quite more voluminous and able to fill the inter-grains pores. On the left side of the natural water content, the curve derived from the PSD curve indicates, at a given suction value, a significantly smaller water content (with only water capillary retention derived from the PSD of the microstructure at $w=14.4 \%$ ) than the real one (with capillarity and water adsorption in the clay aggregates observed in Figure 12, but in the shrinked configuration that they should have under the given suction). Under a suction of $1 \mathrm{MPa}$, the PSD derived curve indicates a water content close to $w=1 \%$ compared to $w=7.5 \%$ of water content remaining in the soil. The strong effect of clay water adsorption (with a $16 \%$ clay fraction) is compatible with the $w=$ $3.5 \%$ water content that the soil is able to retain at a suction as high as $20 \mathrm{MPa}$ (driest point obtained with the wet filter paper).

\section{CONCLUSIONS}

The water retention properties of a natural loess of Northern France have been investigated. This study is part of a wider research program on the hydro-mechanical behaviour of the loess of Northern France conducted with the French Railways company (SNCF) and devoted to the study of stability problems along the North high speed line in collapsible loess.

A high capacity tensiometer (HCT) and the filter paper method were used to obtain the water retention curve of the loess between $10 \mathrm{kPa}$ to about $10 \mathrm{MPa}$ with the filter paper and 0 to $1 \mathrm{MPa}$ with the HCT. The ASTM filter paper method that uses an initially dry filter paper has been complemented by an alternative method in which the filter paper is initially wet. The analysis of the drying branch of the water retention curve of the filter paper suggested that the wet filter paper method allowed to measure a wider range of soil suctions (between $2 \mathrm{kPa}$ and about $10 \mathrm{MPa}$ ). The results confirmed that seven days were sufficient to reach equilibrium for both methods. A good agreement of the suction measurements obtained with the tensiometer and the two filter paper methods was observed and a complete and coherent water retention curve could be obtained.

A microstructural analysis of the natural loess was performed based on Scanning Electron Microscopy and Mercury Intrusion Porosimetry. Both methods provided compatible results evidencing a well graded main pore population with an entrance diameter of around $8 \mu \mathrm{m}$ that characterised the pores between the grains of loess. It was also observed that the $16 \%$ clay fraction was not heterogeneously distributed among the silt grains, with some local aggregations of grains and clay particles.

The shape of the water retention curve appeared to be somewhat specific with a central zone bordering the natural water content $(w=14.4 \%)$ between $w=11 \%$ and $16 \%$ in which no hysteresis was observed. Two hysteretic loops were observed on the dry side $(w<11 \%)$ and the wet side $(w>16 \%)$. The section with no hysteresis is supposed to be related to the natural variations of the water content due to climatic changes. The corresponding estimated maximum and minimum suction values $(20$ and $80 \mathrm{kPa})$ that can be derived should of course be checked by in-situ direct tension measurements.

When comparing the drying path of the experimental WRC with a WRC derived from the PSD curve, a reasonable correspondence was observed at higher water contents in the large pore spaces existing between clean grains, confirming the predominance of capillary effects in this area of the WRC. Conversely, the correspondence was no longer observed at lower water contents and higher suctions, showing the effects of changes in microstructure occurring at the level of clay aggregations and the growing importance of the adsorption of water in the clay fraction at higher suctions. 
Some of the microstructure features evidenced in this work in relation with the water retention properties of the loess could be used in further modelling the loess WRC. This could include for instance i) the separate roles played on the one hand by the inter-grains and interaggregate pores and on the other hand by the intra-aggregate pores inside the clay fraction; (ii) the changes in microstructure during the drying and wetting processes or, more largely, when submitted to hydro-mechanical changes and (iii) the mechanisms that control the water transfers within the complex pore networks that characterise natural soils.

\section{ACKNOWLEDGMENTS}

The present study is part of the first author PhD work. It was mainly supported by the European Alßan Program of high level scholarships for Latin America (scholarship $\mathrm{N}^{\circ}$ E07D402297CO), through grants to Mr. J. Muñoz. The complementary support of the French Railways Company SNCF is also acknowledged.

\section{REFERENCES}

Al-Khafaf S. and Hanks R.J. (1974). Evaluation of the Filter Paper Method for Estimating Soil Water Potential. Soil Science 117 (4). 200-204.

Alonso E., Gens A. and Hight A. (1987). Special problems soils. General Report, Proc. $9^{\text {th }}$ European Conf. on Soil Mechanics and Foundation Engineering, Dublin (3), Balkema. 1087-1146.

Antoine P. (2002). Les loess en France et dans le Nord-Ouest européen. Revue Française de Géotechnique 99. 3-21.

Antoine P., Catt J. and Sommé J. (2003). The Loess and Coversands of Northern France and Southern England. Journal of Quaternary Science 18. 309-318.

Askarinejad A., Casini F., Kienzler P. and Springman S.M. (2011). Comparison between the in situ an laboratory water retention curves for a silty sand. In Proc. $5^{\text {th }}$ Int. Conf. on Unsaturated Soils, Barcelona, CRC Press. 423-428.

ASTM International. (2003). Standard Test Method for Measurement of Soil Potential (Suction) Using Filter Paper, D 5298-03. CASTM International.

Audric T. (1973). Etude Geologique Et Geotechnique Des Limons De Plateau De La Region Parisienne. Bulletin of Engineering Geology and the Environment 8 (1). 49-59.

Aung K.K., Rahardjo H., Leong E.C. and Toll D.G. (2001). Relationship between porosimetry measurement and soil-water characteristic curve for an unsaturated residual soil. Geotechnical and Geological Engineering 19. 401-416.

Barden L., Mc Gown A. and Collins K. (1973). The collapse mechanism in partly saturated soil. Eng. Geol. 7. 49-60.

Bulut R., Hineidi S.M. and Bailey B. (2002). Suction Measurements-Filter Paper and Chilled-Mirror Psychrometer. Proceedings of the Texas Section of the American Society of Civil Engineers Fall 2002 Meeting. Waco, TX., October 2-5, 2002.

Chandler R.J. and Gutierrez, C.I. (1986). The filter-paper method of suction measurement. Geotechnique 36 (2). 265-268.

Cui Y.J., Delage P., Durand F., Schlosser F. and Wojnarowicz M. (1995). Comportement mécanique des loess sur le tracé du TGV Nord. XIème Conférence Européenne de Mécanique des Sols et des Travaux de Fondations, Copenhague, vol. 7.45-50.

Cui Y.J., Marcial M., Terpereau J.M., Delage P., Antoine P., Marchadier G. and Ye W.M. (2004). A geological and geotechnical characterisation of the loess of Northern France. A.W. Skempton Memorial Conference, vol. 1. 417-428.

Cui Y.J., Tang A., Mantho A. and De Laure E. (2008). Monitoring Field Soil Suction Using a Miniature Tensiometer. Geotechnical Testing Journal 31 (1). 95-100.

Delage P. (2010). A microstructure approach of the sensitivity and compressibility of some Eastern Canada sensitive clays. Géotechnique 60 (5). 353-368. 
Delage P., Audiguier M., Cui Y.J. and Howat M.D. (1996). Microstructure of a compacted silt. Can. Geotch. J. 33. 150-158.

Delage P., Tessier D. and Audiguier M. (1982). Use of the Cryoscan apparatus for observation of freeze-fractured planes of a sensitive Quebec clay in scanning electron microscopy. Canadian Geotechnical Journal 19 (1). 111-114.

Delage P. and Lefebvre G. (1984). Study of the structure of a sensitive Champlain clay and of its evolution during consolidation. Canadian Geotechnical Journal 21 (1). 21-35.

Delage P. and Pellerin F.M. (1984). Influence de la lyophilisation sur la structure d'une argile sensible du Québec. Clay Minerals 19. 151-160.

Delage P., Audiguier M., Cui Y.J. and Deveughèle M. (1995). Propriétés de rétention d'eau et microstructure de différents géomatériaux. XIème Conférence Européenne de Mécanique des Sols et des Travaux de Fondations, Copenhague, Vol. 3. 43-48.

Delage P., Cui Y.J. and Antoine P. (2005). Geotechnical Problems related with Loess deposits in Northern France. Proceedings of International Conference on Problematic Soils. 517-540.

Delage P., Marcial D, Cui Y J and Ruiz X. (2006). Ageing effects in a compacted bentonite: a microstructure approach. Géotechnique 56 (5), 291-304.

Delage P., Romero E. and Tarantino S. (2008). Recent developments in the techniques of controlling and measuring suction in unsaturated soils. Keynote Lecture, Proc. $1^{\text {st }}$ Eur. Conf. on Unsaturated Soils, Durham, CRC Press. 33-52.

Diamond S. (1970). Pore size distribution in clays. Clays and clay minerals 18. 7-23.

Fawcett R. and Collis-George N. (1967). A Filter paper Method for Determining the Moisture Characteristics of Soil. Australian Journal of Experimental Agriculture and Animal Husbandry 7. 162-167.

Gardner R. (1937). A Method of Measuring the Capillary Tension of Soil Moisture Over a Wide Moisture Range. Soil Sci. 43. 277-283.

Gens A. and Nova R. (1993). Conceptual bases for a constitutive model for bonded soils and weak rocks. Proc. Int. Symp. on Hard Soils \& Soft Rocks 1, Athens. 485-494.

Greacen E.L., Walker G.R., and Cook P.G. (1987). Evaluation of the Filter Paper Method for Measuring Soil Water Suction. International Conference on Measurement of Soil and Plan Water Status. 137-143.

Hamblin A.P. (1981). Filter Paper Method for Routine Measurement of Field Water Potential. $J$. Hydrol. 53. 355-360.

Harrison B. and Blight G. (1998). The Effect of Filter Paper and Psychrometer Calibration Techniques on Soil Suction Measurements. Proceedings of the Second International Conference on Unsaturated Soils 1. Beijing: International Academic Publishers. 362-367.

Hillel, D. (1971). Soil and water: Physical principles and processes. Academic, New York

Hormdee D. (2008). Investigation on Collapse Potential of Loess Soil. Proceedings of the 18th International Offshore and Polar Engineering Conference, Vol. 2. Fontaine E., Uchida K., Chung J.S. et Moshagen H. (Eds.). 579-583.

Houston S.L., Houston W.N. and Wagner A.M. (1994). Laboratory filter-paper suction measurements. Geotechnical Testing Journal 17 (2). 185-194.

Karam J.P. (2006). Etude de la rhéologie des loess du Nord de la France. Application à l'évaluation de leur risque de liquéfaction. $\mathrm{PhD}$ thesis. École Nationale des Ponts et Chaussées. Paris.

Kenton C.P., Vanapalli S.K. and Garga V.K. (2008). A Revised Contact Filter Paper Method. Geotechnical Testing Journal 31 (6). 461-469.

Konyai S., Sriboonlue V., Trelo-ges V. and Muangson N. (2006). Hysteresis of water retention curve of saline soil. In Proceedings of the Fourth International Conference on Unsaturated Soils, Carefree, ASCE. 1394-1404.

Koliji A., Vulliet L. and Laloui L. (2010). Structural characterization of unsaturated aggregated soil. Canadian Geotechnical Journal 47 (3). 297-311

Le T.T., Delage P., Cui Y.J., Tang A.M., Lima A., Romero E., Gens A. and Li X.L. (2008). Water retention properties of Boom Clay: A comparison between different experimental techniques. In Proc. $1^{\text {st }}$ Eur. Conf. on Unsaturated Soils, Durham, CRC Press. 229-234.

Leong E., He L. and Rahardjo, H. (2002). Factors Affecting the Filter Paper Method for Total and Matric Suction Measurements. Geotechnical Testing Journal 25 (3). 322-333. 
Leroueil S. and Barbosa A. (2000). Combined effect of fabric, bonding and partial saturation on yielding of soils. In Asian Conference on Unsaturated Soils. 527-532.

LLoret A., Villar M.V., Sanchez M., Gens A., Pintado X. and Alonso E.E. (2003). Mechanical behaviour of heavily compacted bentonite under high suction changes. Géotechnique 53 (1). $27-$ 40.

Mantho A. (2005). Echanges sol - atmosphère: application à la sécheresse. $\mathrm{PhD}$ thesis. École Nationale des Ponts et Chaussées. Paris.

Marinho F. and Oliveira O. (2006). The Filter Paper Method Revisited. Geotechnical Testing Journal 29 (3). 250-258.

McQueen I.S. and Miller R.F. (1968). Calibration and Evaluation of a wide-range gravimetric method for measuring moisture stress. Soil Science 106 (3). 225-231.

Parcevaux P. (1980). Étude microscopique et macroscopique du gonflement de sols argileux. $\mathrm{PhD}$ thesis. École Nationale Supérieure des Mines de Paris.

Patrick P.K., Olsen H.W. and Higgins J.D. (2007). Comparison of Chilled-Mirror Measurements and Filter Paper Estimates of Total Suction. Geotechnical Testing Journal 30 (5). 360-367.

Pécsi M. (1990). Loess is not just the accumulation of dust. Quaternary International 7/8. 1-21.

Pham H.Q., Fredlund D.G., and Barbour S. L. (2005). A study of hysteresis models for soil-water characteristic curves. Can. Geotech. J. 42. 1548-1568

Prapaharan S., Altschaeffl A.G. and Dempsey B.J. (1985). Moisture Curve of Compacted Clay Mercury Intrusion Method. Journal of Geotechnical Engineering - ASCE 111 (9). 1139-1146.

Punrattanasin P. (2008). The capacity of improved Khon Kaen Loess as a road construction material. 1st International Conference on Transportation Geotechnics, Nottingham, England, Aug. 25-27, 2008. In: Advances in Transportation Geotechnics, Ellis E., Yu H.S., McDowell G. Dawson A. et Thom N. (eds.). 535-540.

Ridley A. (1995). Discussion on 'Laboratory Filter Paper Suction Measurements' by Sandra L. Houston, William N. Houston, and Anne-Marie Wagner. Geotechnical Testing Journal 18 (3). 391-396.

Ridley A. and Burland J. (1993). A new instrument for the measurement of soil moisture suction. Géotechnique 43 (2). 321 - 324.

Ridley A. and Burland J. (1995). Measurement of suction in materials which swell. Applied Mechanics Reviews 48 (9). 727-732.

Ridley, A.M. and Burland, J.B. (1999). Discussion: Use of tensile strength of water for the direct measurement of high soil suction. Canadian Geotechnical Journal 36. 178-180.

Romero E. (1999). Characterisation and thermo-hydro-mechanical behaviour of unsaturated Boom clay: an experimental study. $\mathrm{PhD}$ thesis. Universitat Politécnica de Catalunya. Barcelone.

Simms P.H. and Yanful E.K. (2001). Measurement and estimation of pore shrinkage and pore distribution in a clayey till during soil-water characteristic curve tests. Canadian Geotechnical Journal 38 (4). 741-754.

Simms P.H. and Yanful E.K. (2002). Predicting soil-water characteristic curves of compacted plastic soils from measured pore-size distribution. Géotechnique 52 (4). 269-278.

Sridharan A. Altschaeffl A.G. and Diamond S. (1971). Pore size distribution studies. Journal of the Soil Mechanics and Foundation Division, ASCE 97. 771-787.

Swarbrick G.E. (1995). Measurement of soil suction using the filter paper method. First International Conference on Unsaturated Soils, E.E. Alonso and P. Delage (eds), Vol. 2, Paris. 701-708.

Tarantino A. (2004). Direct measurement of soil water tension. Unsaturated Soils, Jucá, de Campos \& Marinho (eds). Swets \& Zeitlinger, Lisse, ISBN 9058093719.

Tarantino A. and De Col E. (2008). Compaction behaviour of clay. Géotechnique 58(3). 199-213.

Tarantino A. and Mongiovì L. (2001). Experimental procedures and cavitation mechanisms in tensiometer measurements. Geotechnical and Geological Engineering 19. 189-210.

Vázquez M., Durand P. and Justo J.L. 2011). Soil-Water Characteristic Curve (SWCC) and volumetric deformation law for a plastic clay under high suction. In Proc. $5^{\text {th }}$ Int. Conf. on Unsaturated Soils, Barcelona, CRC Press. 509-512.

Yang C., Cui Y.J., Pereira J.M. and Huang M.S. (2008). A constitutive model for unsaturated cemented soils under cyclic loading. Computers and Geotechnics 35(6). 853-859. 
Yuan Z.X. and Wang L.M. (2009). Collapsibility and seismic settlement of loess. Engineering Geology 105 (1)-(2). 119-123.

Yudhbir (1982). Collapsing behaviour of residual soils. Proc. 7th Southeast Asian Geotech. Conf., Hong-Kong 1. 915-930. 